\title{
Coercivity and its thermal dependence in microsized magnetic particles: Influence of grain boundaries
}

\author{
P. Marín, ${ }^{1, a)}$ A. M. Aragón, ${ }^{1}$ A. García Escorial, ${ }^{2}$ M. Lieblich, ${ }^{2}$ P. Crespo, ${ }^{1}$ and A. Hernando ${ }^{1}$ \\ ${ }^{1}$ Instituto de Magnetismo Aplicado, IMA, P.O. Box 155, 28230 Madrid, Spain \\ ${ }^{2}$ CENIM-CSIC, Spanish National Center for Metallurgical Research-Spanish National Research Council, \\ Avda, Gregorio del Amo, 8, 28040 Madrid, Spain
}

(Received 6 November 2012; accepted 4 January 2013; published online 24 January 2013)

\begin{abstract}
$\mathrm{Fe}_{73.5} \mathrm{Si}_{13.5} \mathrm{~B}_{9} \mathrm{Nb}_{3} \mathrm{Cu}_{1}$ powder particles have been obtained by gas atomization. Magnetization curves and coercivity were studied for particles ranging in size up to $1000 \mu \mathrm{m}$. The overall magnetic behavior of such material is a consequence of compositional heterogeneity of the microstructure as a whole. Anomalous temperature variation of coercivity $\left(\mathrm{H}_{\mathrm{c}}\right)$ (i.e., a decrease in $\mathrm{H}_{\mathrm{c}}$ with decreasing temperature) together with a decrease of saturation magnetization has been observed for less than $25 \mu \mathrm{m}$ size. The origin of this behavior has been ascribed to metastable $\mathrm{FeCu}$ and FeNbSi phases in combination with an Fe-rich one. Making magnetic powders with coercive fields of the order of mOe remains a challenge for researchers. Our experiment has allowed us, at low temperature, achieving a coercive field of 9 Oe, much lower than those observed so far in this type of materials. This behaviour has been related with a $\mathrm{FeCu}$ phase present on grain boundaries. (C) 2013 American Institute of Physics. [http://dx.doi.org/10.1063/1.4788808]
\end{abstract}

\section{INTRODUCTION}

In the last decades, nanocrystalline and nanogranular magnetic materials have attracted a great deal of interest due to their non-conventional physical, chemical, and magnetic properties. ${ }^{1-3}$ Microstructural design can be done by means of composition, preparation procedure, and annealing temperature. The size of the grains and the distance between them are factors determinant of sample magnetic behavior when they are embedded in a matrix formed by a different phase. ${ }^{4-13}$ In these alloys, the exchange coupling between the crystals is mediated through the grain boundaries. The impurities and the impurity-containing phases are generally concentrated in the interface between grains ${ }^{14-19}$ but it is usually a very difficult task to separate those impurities from the grain boundaries. These factors affect the magnetic behavior of granular nanostructures, which are the source of surface anisotropy but also essentially modulate, as stated above, the couplings between the grains that occur across the interface. In particular, a spinglass-like freezing of the grain boundary region was indicated, in nanocrystalline $\mathrm{Fe}$, as the main responsible for the change from the high-temperature regime, exchange interaction controlled, to the low-temperature glassy state, where exchange interactions are not transmitted to adjacent grains. ${ }^{19}$ In other cases, the low temperature coupling between grains gradually disappears as temperature rises as the local Curie temperature of the boundary is approached. ${ }^{4}$

In this article, we have studied the magnetic behavior of microsized powders of $\mathrm{Fe}_{73.5} \mathrm{Si}_{13.5} \mathrm{~B}_{9} \mathrm{Nb}_{3} \mathrm{Cu}_{1}$ obtained by gas atomization. The study focuses on the influence of grain boundaries nature, modified by cooling rate and thermal treatments, on coercivity. Previous works show how the coercivity of this

\footnotetext{
a) Author to whom correspondence should be addressed. Electronic addresses: mpmarin@fis.ucm.es and pmarinpalacios@gmail.com. Tel.: +34913007175. Fax: +34913007176.
}

composition is much larger for powders than that for melt-spun ribbons, although the saturation magnetization is the same. ${ }^{18}$ This behavior has been ascribed to the absence of the inter-grain amorphous ferromagnetic phase, characteristics of annealed ribbons, resulting in a weakening of the exchange coupling between the nanograins. ${ }^{4-6}$ Prior powder particles of $\mathrm{Fe}_{73.5} \mathrm{Si}_{13.5} \mathrm{~B}_{9} \mathrm{Nb}_{3} \mathrm{Cu}_{1}$ have been obtained using two methods (gas atomization and ball milling of melt-spun ribbons) in order to show the analogies and differences between both materials. ${ }^{20}$ Furthermore, gas atomized $\mathrm{Fe}_{73.5} \mathrm{Si}_{13.5} \mathrm{~B}_{9} \mathrm{Nb}_{3} \mathrm{Cu}_{1}$ and $\mathrm{Fe}_{93} \mathrm{Si}_{7}$ were investigated to study the influence of alloying elements. ${ }^{21}$ Moreover, it was observed that for the same powder particle size and similar grain size the coercive field of $\mathrm{Fe}_{73.5} \mathrm{Si}_{13.5} \mathrm{~B}_{9} \mathrm{Nb}_{3} \mathrm{Cu}_{1}$ was almost one order of magnitude higher than those of the $\mathrm{Fe}_{93} \mathrm{Si}_{7}$ alloy. ${ }^{22}$

The experimental results shown in this article, analyzed in combination with previous observations on the particle size dependence of coercivity, ${ }^{23}$ illustrate the importance of microstructure, phase coexistence, and grain boundaries on the magnetic behavior of microsized powders. The previous work to which Ref. 23 shows how, when powder particle size is smaller than the domain size, coercivity should decrease with increasing particle volume, $\mathrm{v}$, as $1 / \mathrm{v}^{1 / 2}$. Such experimental observation was explained by assuming a constant grain size and a single magnetic phase. The present article analyzes the consequences, on magnetization and coercivity behavior, of the coexistence of several phases.

\section{EXPERIMENTAL}

\section{A. Sample preparation}

Atomized powder particles of composition $\mathrm{Fe}_{73.5} \mathrm{Si}_{13.5}$ $\mathrm{B}_{9} \mathrm{Nb}_{3} \mathrm{Cu}_{1}$, expressed in atomic percent, were obtained by means of the CENIM gas atomizer from $\mathrm{Fe}-\mathrm{Nb}$ and $\mathrm{Fe}-\mathrm{Si}$ master alloys and $\mathrm{B}$ and $\mathrm{Cu}$ pure elements. The alloy was melted and superheated $200{ }^{\circ} \mathrm{C}$ above the liquid temperature 
in a magnesia crucible, the superheated melt was poured into a tundish, and atomisation of the melt was achieved at the tundish exit by an annular jet of argon at 2.3 MPa giving a gas flow rate of $3.7 \mathrm{~kg} \mathrm{~min}{ }^{-1} .^{20,21}$ The powder is collected and sieved into different powder particle sizes: $-25 \mu \mathrm{m}$ (sample A), 25-50 $\mu \mathrm{m}$ (sample B), 50-125 $\mu \mathrm{m}$ (sample C), 125$250 \mu \mathrm{m}$ (sample D), 250-500 $\mu \mathrm{m}$ (sample E), 500-1000 $\mu \mathrm{m}$ (sample F). This work is focused on the small, less than $25 \mu \mathrm{m}$, samples, denominated A, and the largest 500-1000 $\mu \mathrm{m}$ samples, denominated $\mathrm{F}$, size ranges. In order to study the evolution samples A and $\mathrm{F}$ have been annealed $1 \mathrm{~h}$ at $700^{\circ} \mathrm{C}$, and denominated sample A-A and sample F-A, respectively.

\section{B. Sample characterization}

The powder was studied by X-ray diffraction (XRD) using $\mathrm{Cu}-\mathrm{K} \alpha$ radiation as shown in Fig. 1. The microstructure of the powder was observed by scanning electron microscopy (SEM) equipped with X-ray energy dispersive analysis unit (EDX). Contrast images of electron channeling have been taken, which are produced from electrons with channel down the crystal planes, and, thus, are sensitive to crystallographic orientation. Hysteresis loops temperature dependence and magnetization versus temperature were measured using a Physical Property Measurement System vibrating sample magnetometer (PPMSVSM). Quantum Design for the temperature range comprised between 4 and $300 \mathrm{~K}$ and with a maximum field of $4 \mathrm{~T}$, on encapsulated samples.

\section{RESULTS}

\section{A. Microstructural characterization of the samples}

$\mathrm{X}$-ray patterns of as-atomized powder as a function of particle size are shown in Fig. 1. An iron-rich phase with the main peak positioned in $2 \theta=45.1^{\circ}$ in combination with a ternary $\mathrm{Fe}_{16} \mathrm{Nb}_{6} \mathrm{Si}_{7}$ phase with a weak trace positioned in $2 \theta=43.89^{\circ}$ can be distinguished in the diffractogram corresponding to sample A. The observation of patterns associated with other particle sizes leads to the following conclusions. The trace in $2 \theta=43.89^{\circ}, \mathrm{Fe}_{16} \mathrm{Nb}_{6} \mathrm{Si}_{7}$ signal, becomes less important as particle size increases, and even disappears in the diagrams associated with samples $\mathrm{E}$ and $\mathrm{F}$, which show only the Bragg peaks corresponding to the Fe-rich phase.
The X-ray diagram obtained for powders A-A and F-A is also included. In the case of small particle size (sample A-A), the high intensity peak in the position $2 \theta=45.1^{\circ}$ is found in combination with signals of $\mathrm{Fe}_{16} \mathrm{Nb}_{6} \mathrm{Si}_{7}$ and $\mathrm{Fe}_{2} \mathrm{Si}$ phases and pure $\mathrm{Si}$ and pure $\mathrm{Cu}$ traces. Sample $\mathrm{F}$ microstructure is more stable. This is evidenced by thermal treatment that keeps it almost unchanged.

The main peak of the iron rich phase is shown in detail in the inset. A clear displacement of this peak to the right, accompanied by an intensity decrease, is observed as particle size increases. The $2 \theta$ diffraction angles, associated to the main Bragg peak, are in a range between $45.05^{\circ}$ and $45.58^{\circ}$. These differences should be connected with lattice distortion due to alloying elements diffusion. In fact, the main Bragg peak associated with $\mathrm{Fe}_{3} \mathrm{Si}$ should be found at $45.337^{\circ}$. This is exactly the peak position observed for samples with particle size in the range $250-500 \mu \mathrm{m}$. The silicon presence in the lattice decreases with particle size and seems to be connected with cooling rate.

Fig. 2 shows the main peak position as a function of particle size for the as-atomized and annealed powder. In the case of the small powder, we would have a supersaturated solid solution of $\alpha-\mathrm{Fe}, \mathrm{Si}, \mathrm{B}, \mathrm{Nb}$, and $\mathrm{Cu}$ in solution. $\mathrm{Cu}$ has little affinity with other elements and, as indicated by mapping, it is rejected to the grain boundary. By increasing the size of dust, cooling process would be slower and, therefore, the crystallization of the magnetic $\mathrm{Fe}_{3} \mathrm{Si}$ phase would be possible decreasing the single elements in solid solution.

Figure 3 shows the influence of annealing on sample A in detail. The small trace, indicated with "a" found in $2 \theta=43.89^{\circ}$ for sample $\mathrm{A}$, coexists with the $\alpha-\mathrm{Fe}(\mathrm{Si})$ and $\mathrm{Fe}_{16} \mathrm{Nb}_{6} \mathrm{Si}_{7}$ phases. The position of this peak is between fcc- $\mathrm{Cu}\left(2 \theta=43.47^{\circ}\right)$ and bcc-Fe $\left(2 \theta=44.67^{\circ}\right)$ main diffraction peaks. The possibility of having an $\mathrm{FeCu}$ metastable phase should be considered. This pattern suffers a clear evolution upon annealing as shown in Fig. 3, sample A-A. The trace initially found at $2 \theta=43.89^{\circ}$ has been unfolded in two peaks. One more left to be identified with pure fcc$\mathrm{Cu}$ and a second one in the right that fits with $\mathrm{Fe}_{2} \mathrm{Si}$. Pure silicon trace $\left(2 \theta=47.3^{\circ}\right)$ is also observed.

Fig. 4 shows backscattered SEM micrographs of cross sections of as atomized powder of size below $25 \mu \mathrm{m}$ (sample

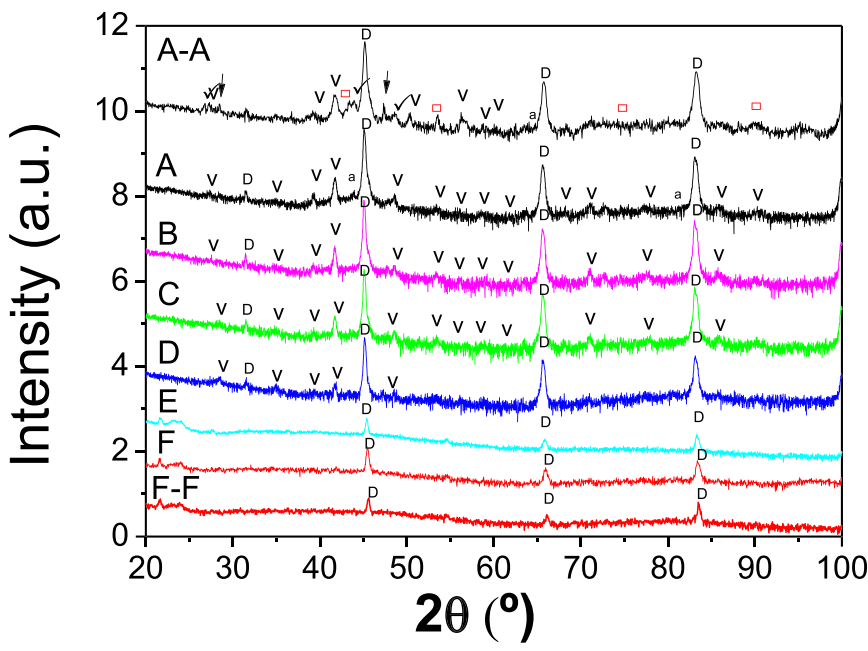

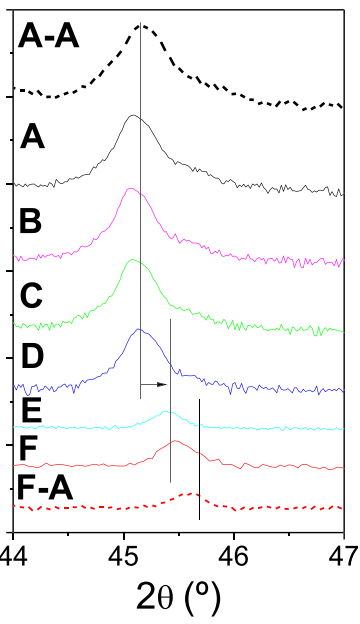

FIG. 1. Influence of particles size on X-ray diffraction patterns for $2 \theta$ between $20^{\circ}$ and $100^{\circ}$ (a) and first Bragg peak detail (b) for as-atomised powder: $-25 \mu \mathrm{m}$ (A), 25$50 \mu \mathrm{m}$ (B), 50-125 $\mu \mathrm{m}$ (C), $125-250 \mu \mathrm{m}$ (D), 250-500 $\mu \mathrm{m}$ (E), $500-1000 \mu \mathrm{m} \quad(\mathrm{F})$, and annealed at $700{ }^{\circ} \mathrm{C}-25 \mu \mathrm{m}$ (A-F) and 500-1000 $\mu \mathrm{m}$ (F-A). Phases identification: v $\mathrm{Fe}_{16} \mathrm{Nb}_{16} \mathrm{Si}_{7}, \quad \mathbf{D} \alpha-\mathrm{Fe}(\mathrm{Si}), \mathrm{Fe}_{3} \mathrm{Si}, \quad$ a $\alpha-\mathrm{Fe}(\mathrm{Cu}), \square \mathrm{Cu}, \downarrow \mathrm{Si}, \checkmark \mathrm{Fe}_{2} \mathrm{Si}$. 


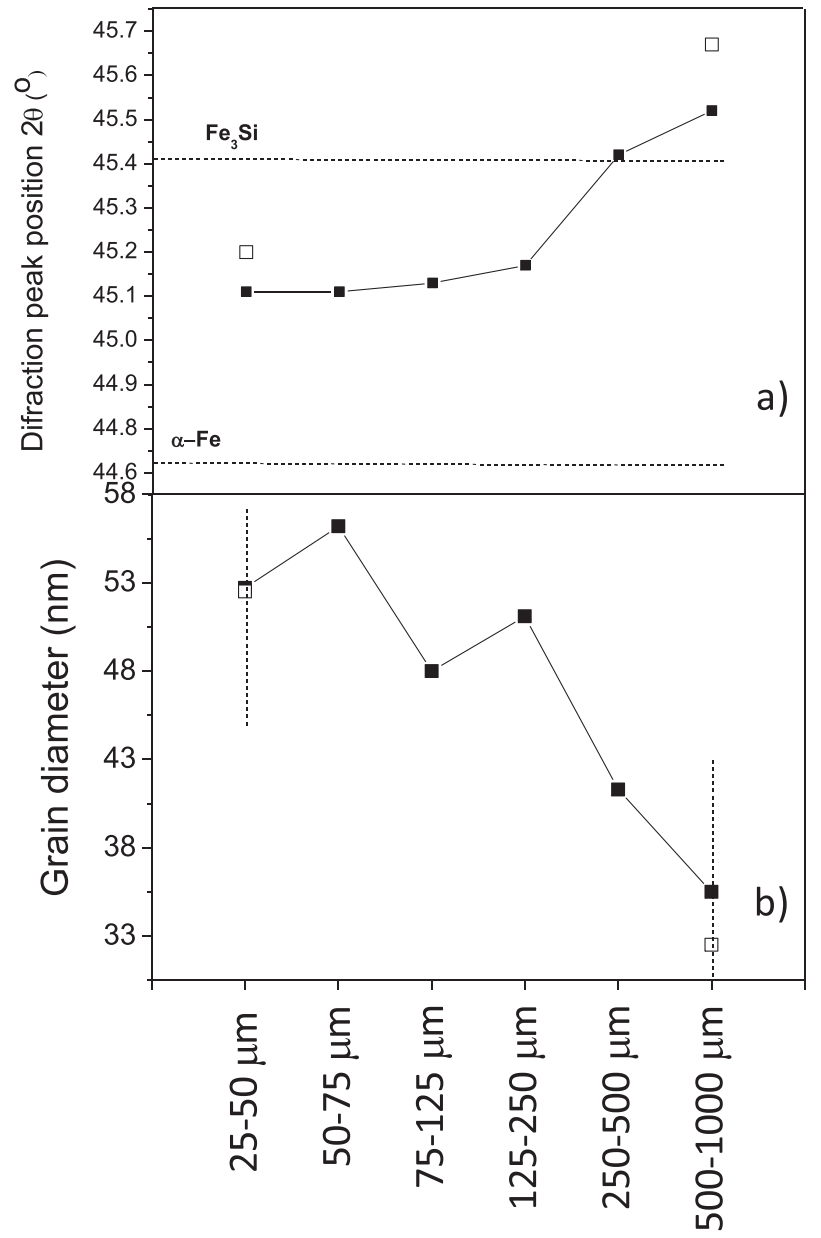

FIG. 2. Main diffraction peak position as a function of particle size for asatomized (ם) and annealed at $700^{\circ} \mathrm{C}$ samples ( $\square$ ).

A) and over $500 \mu \mathrm{m}$ (sample F), respectively. In the first case, a homogeneous and fine microstructure of grains, of around $5 \mu \mathrm{m}$ in size, of different contrast is observed. The $500-1000 \mu \mathrm{m}$ (sample F) particles show a structure of dendrite grains of around $25 \mu \mathrm{m}$ in size.

Fig. 5(a) shows a micrograph of as-atomized powder under $25 \mu \mathrm{m}$ (sample A), where a $\mathrm{Cu}$ segregation at the grain boundaries can be speculated from Electrons Dispersive Scattering (EDS) signals. Fig. 5(b) shows a micrograph of a particle in the same size range annealed $1 \mathrm{~h}$ at $700^{\circ} \mathrm{C}(\mathrm{A}-\mathrm{A})$. In this sample, bright precipitates at the grain boundaries are clearly seen. EDS analysis of these precipitates, Fig. 5(c) shows that they are $\mathrm{Cu}$-rich in good agreement with the $\mathrm{X}$-ray
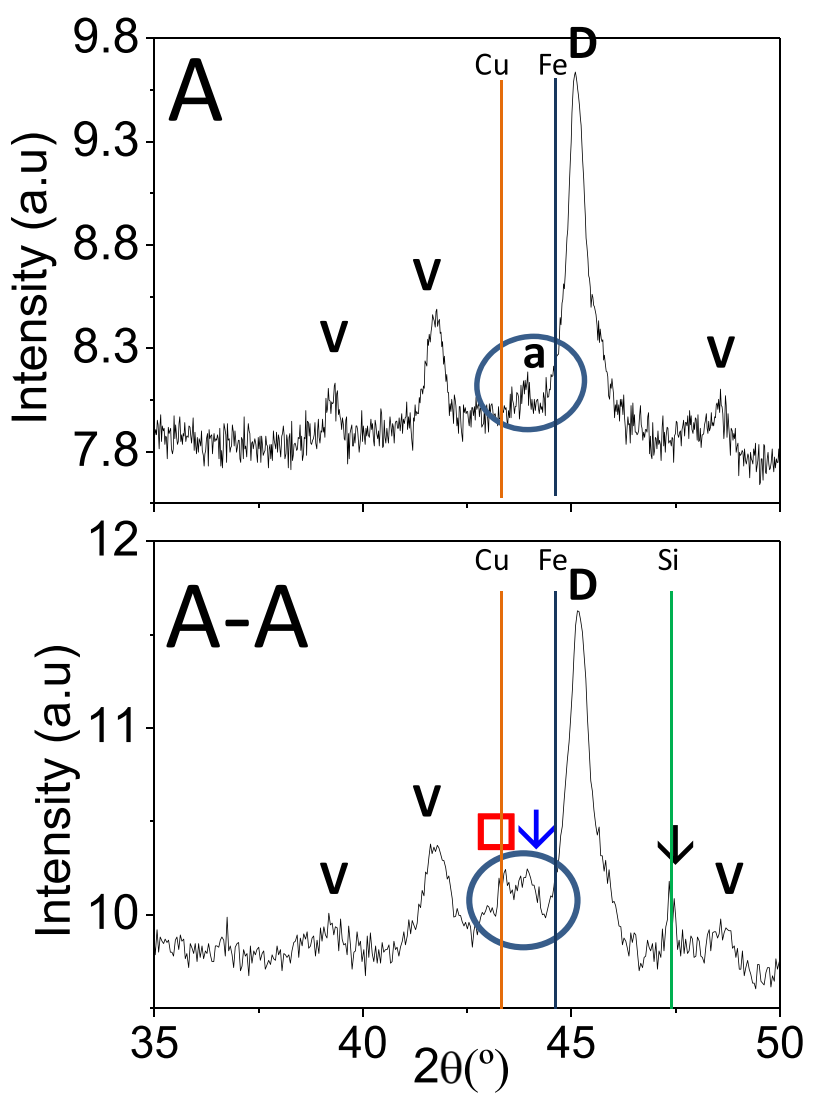

FIG. 3. Details of X-ray diffraction pattern for under $25 \mu \mathrm{m}$ powder: asatomised (sample A) and annealed at $700{ }^{\circ} \mathrm{C}$ (sample A-A). Phases identification: v Fe ${ }_{16} \mathrm{Nb}_{16} \mathrm{Si}_{7}, \mathbf{D} \alpha-\mathrm{Fe}(\mathrm{Si}), \mathrm{Fe}_{3} \mathrm{Si}, \mathbf{a} \alpha-\mathrm{Fe}(\mathrm{Cu}), \square \mathrm{Cu}, \downarrow \mathrm{Si}, \checkmark \mathrm{Fe}_{2} \mathrm{Si}$.

diffractograms shown in Fig. 1. It is important to remark that for largest particles no similar $\mathrm{Cu}$ aggregates were observed for neither as-atomized nor annealed samples for both SEM and X-ray diffraction techniques. This difference becomes crucial as concerns magnetic behaviour, as outlined below.

\section{B. Magnetic properties}

We report hereafter the main results obtained on the magnetic properties. The first point under consideration has been powder particle size influence on hysteresis loop. Fig. 6 shows RT positive branch of the loop for different powder sizes under study. The corresponding coercivity field and magnetization are shown in the inset. The influence of $700^{\circ} \mathrm{C}$ annealing on samples $\mathrm{A}$ and $\mathrm{F}$ is also included. A decrease of

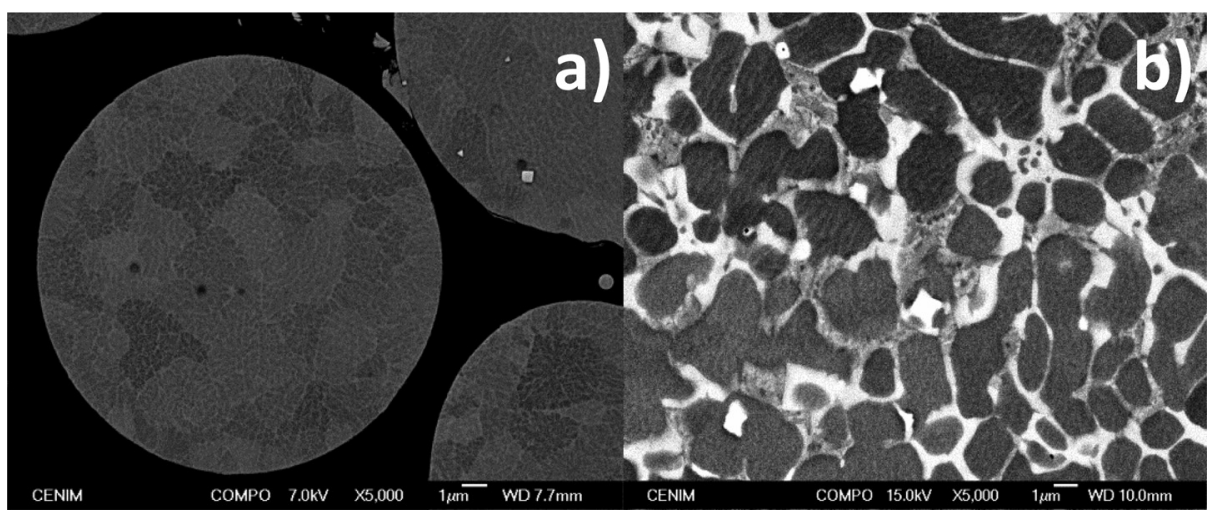

FIG. 4. SEM micrographs of as-atomized under 25, (a), and above $500 \mu \mathrm{m}$, (b) powder. 


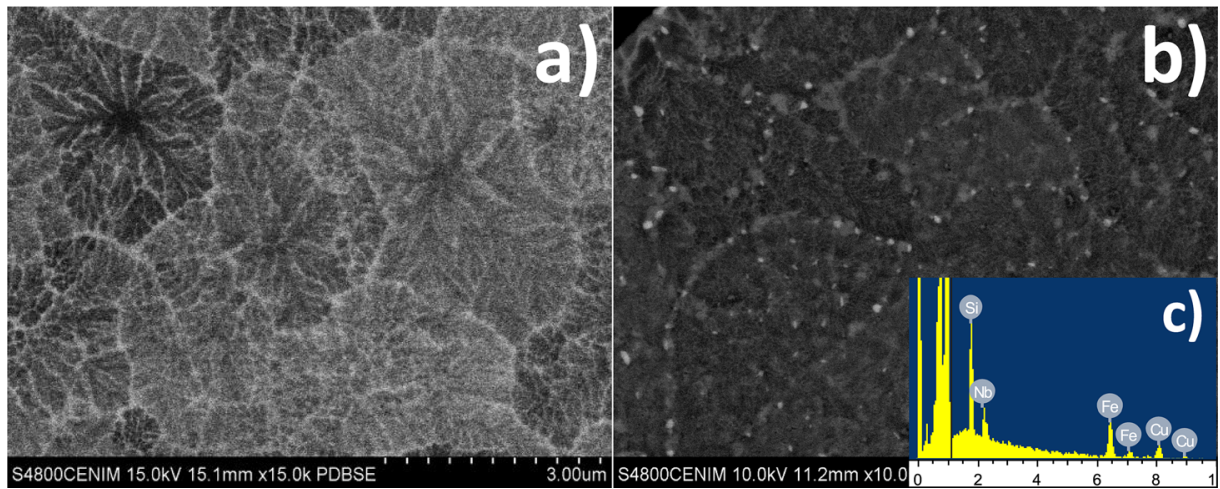

FIG. 5. SEM micrographs of under $25 \mu \mathrm{m}$ powder (a) as-atomised, (b) annealed at $700^{\circ} \mathrm{C}$, and (c) spectrum of a bright precipitate in (b).

coercivity when particle size increases is observed and found to be in agreement with previous works on size dependence of coercivity in single-phase magnetic particles. ${ }^{18}$ The difference between coercivity of smaller and largest particle is incremented after annealing. The reduction of particle size results in a decrease of saturation magnetization. This behavior should be ascribed to microstructural features related with the presence of $\mathrm{Fe}_{16} \mathrm{Nb}_{6} \mathrm{Si}_{7}$ and $\mathrm{Fe}(\mathrm{Cu})$ phases. The annealing has, also, some influence on these parameters. The heat treatment performed on sample A leads to a clear saturation magnetization increase probably connected with $\mathrm{Cu}$ precipitation and formation of $\mathrm{Fe}_{2} \mathrm{Si}$ phase. The effect on sample $\mathrm{F}$ is similar but weaker and probably related with $\mathrm{Fe}_{3} \mathrm{Si}$ grains growth.

To further analyze the magnetic behavior of these samples, it has been chosen the larger, above $500 \mu \mathrm{m}$ (sample F), and smaller, below $25 \mu \mathrm{m}$ (sample A), to be studied at low temperature. Fig. 7 shows coercivity evolution with temperature for samples A, F, A-A, and F-A, respectively. The analysis of this figure yields to the following considerations. While the coercive field of the large sample (F) decreases with increasing temperature the smaller sample (A) behaves conversely presenting much lower coercivities at low temperature. Moreover, sample $\mathrm{F}$ after heat treatment keeps the same tendency for coercivity with temperature and the only difference observed in the curve is a displacement of 10 Oe to lower

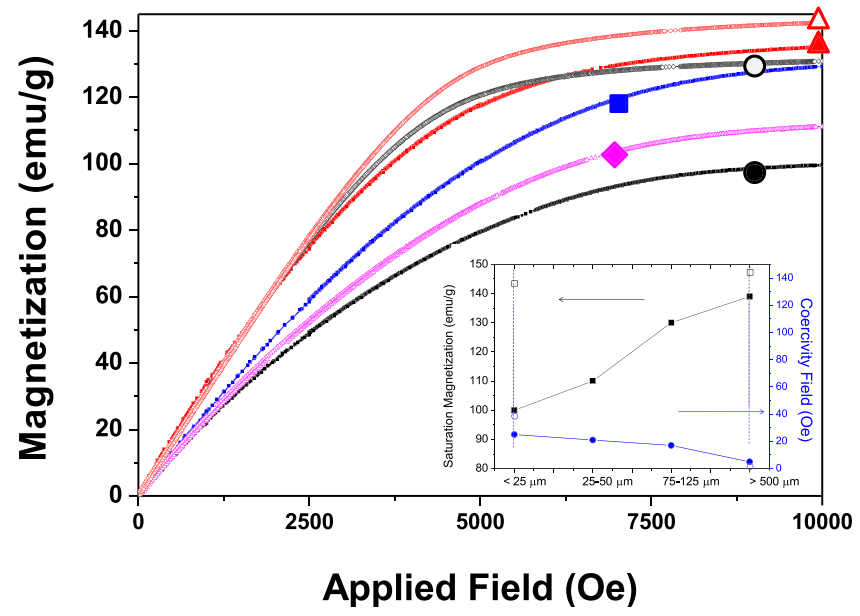

FIG. 6. Influence of particle size on magnetization curves. The corresponding coercivity field $(\mathbf{O})$ and magnetization $(\square)$ for as-milled and annealed at $700^{\circ} \mathrm{C}$ (coercivity $(\bigcirc)$ and magnetization $(\square)$ ) are shown in the inset. coercivity field but sample A turns its behavior after annealing presenting a decrease of coercivity with measuring temperature. It should be noted how, in this case, the coercivity values obtained are 40 Oe larger than those of sample F-A.

Saturation magnetization as a function of temperature for samples A, F, A-A, and A-F is shown in Fig. 8. When comparing the as-atomized samples, an almost constant difference of $25 \mathrm{emu} / \mathrm{g}$ is observed over the whole range of temperatures. Sample F is the one with higher value of saturation magnetization. Annealing leads to an increase in the saturation magnetization values for both samples but keeps a difference between the values of samples $\mathrm{A}$ and $\mathrm{F}$ of $12 \mathrm{emu} / \mathrm{g}$.

\section{DISCUSSION}

The anomalous behavior of coercivity with the temperature for the as-atomized powder with size under $25 \mu \mathrm{m}$ (sample A) should be justified by means of powder microstructure. The high cooling rate associated to these small particle size has resulted in a metastable structure where a supersaturated bcc $\mathrm{Fe}(\mathrm{Si})$, single domain phase, coexists with an FeNbSi phase and with other $\mathrm{Fe}$ rich phases distorted by $\mathrm{Cu}$ presence in the lattice. The grain structure can be envisaged as an assembly of monodomain crystallites, i.e., the grains, embedded in a matrix that is formed by the grain boundaries. ${ }^{4}$ It can be considered that, as metastable $\mathrm{Cu}$ diluted in bcc-Fe segregates through a process of spinodal decomposition, the rapidly

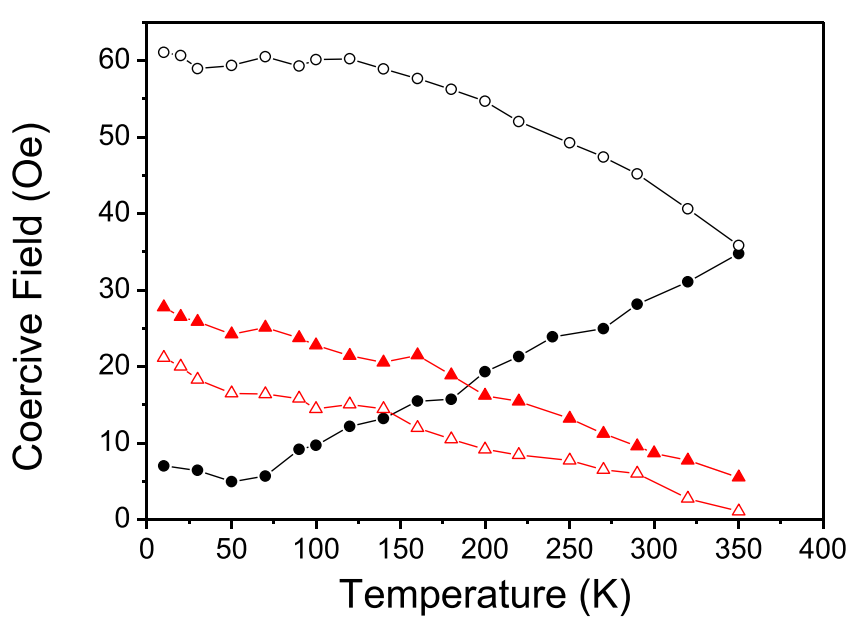

FIG. 7. Thermal dependence of the coercive field for powder under 25 and 500-1000 $\mu \mathrm{m}$ : as-atomised and annealed at $700^{\circ} \mathrm{C}$. 


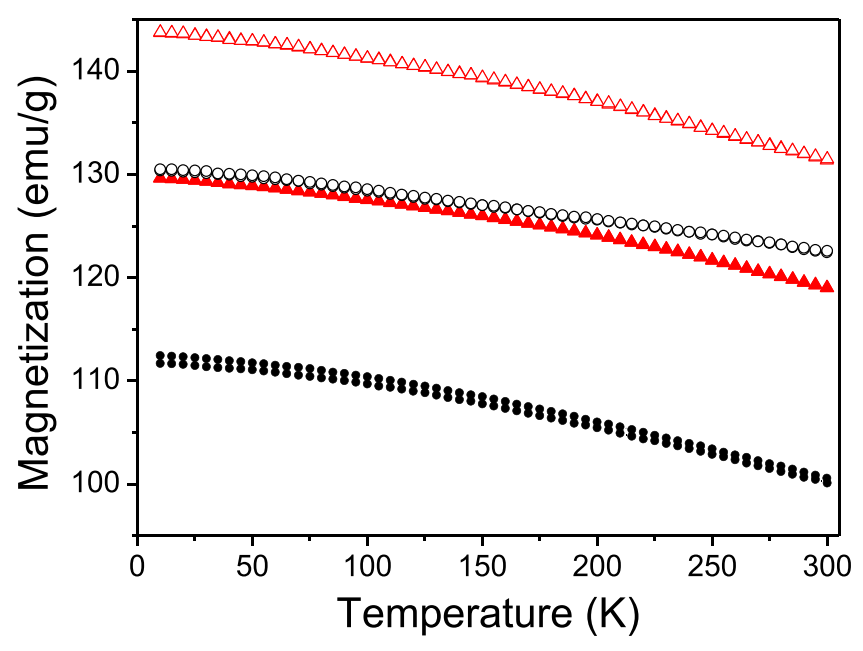

FIG. 8. Thermal dependence of the magnetization, measured at $1 \mathrm{~T}$, for asatomised powder under 25 and $500-1000 \mu \mathrm{m}$ : as-atomised, A and F, respectively, and annealed at $700{ }^{\circ} \mathrm{C}, \mathrm{A}-\mathrm{A}$ and F-A, respectively.

solidified powders contain at the grain boundaries a spectrum of $\mathrm{Fe}_{\text {rich }}-\mathrm{Cu}_{\text {poor }}$ local compositions. ${ }^{24}$ As reported in Refs. 25 and 16 , for low temperatures the different $\mathrm{Fe}-\mathrm{Cu}$ regions are ferromagnetic with a wide range of Curie temperatures depending on the particular composition. Therefore, at low temperatures the grain boundaries are mainly ferromagnetic allowing the coupling between the bcc nanocrystals. Such inter-grain coupling should increase the exchange correlation length, reducing the wall pinning forces, and decrease the coercivity, as shown in Fig. 7. However, as the temperature rises some local spinodal phases gradually reach its Curie temperature and become paramagnetic. This magnetic transformation reduces the strength of the inter-grain exchange yielding progressive magnetic decoupling between single domain bcc Fe-rich particles. ${ }^{4}$

After annealing, the $\mathrm{Cu}$ is totally segregated from bcc-Fe and precipitates forming at the boundaries clusters with size sufficiently large as to be clearly detected by x-ray diffraction and SEM as illustrated in Figs. 1 and 5(b), respectively. By the effect of these $\mathrm{Cu}$ precipitates the grain become magnetically isolated and the low temperature coercivity increases as shown in Fig. 7. Moreover, the thermal dependence of the coercivity turns out to be now completely normal as can be observed in Fig. 7. The experimentally found $\mathrm{Cu}$ segregation should also be connected with the increase of saturation magnetization, from 112 up to $131 \mathrm{emu} / \mathrm{gr}$, achieved after annealing as shown in Figs. 6 and 8.

Note that for powders, F, with higher particle size and characterized by slower cooling rates $\mathrm{Cu}$ is not observed. The thermal dependence of coercivity is that expected for both as-atomized and annealed F samples. However, the saturation magnetization also increases with annealing from 130 up to $145 \mathrm{emu} / \mathrm{gr}$. (Fig. 8). The modification of the saturation magnetization should be associated with the phase distribution in the as-atomized and annealed particles. Subtle modifications of the Fe-rich magnetic phase are suggested by the shift of the corresponding X-ray diffraction peak depicted in Fig. 2(a) as a function of the particle size. The effect of the annealing is also shown for samples $\mathrm{A}$ and $\mathrm{F}$ in the same figure. A clear correlation is appreciated between the diffraction peak position and the room temperature magnetization measured at $1 \mathrm{~T}$ and shown in Fig. 6.

\section{CONCLUSIONS}

The observed differences in phases and the corresponding modifications detected after annealing are correlated with the measured changes of the magnetization and coercivity. The dramatic influence of $\mathrm{Cu}$ content on the coercivity and its thermal dependence in smallest size sample contrasts with the absence of $\mathrm{Cu}$ influence hints in the magnetic behavior of large size powders. The trend to approach a large magnetization $\mathrm{Fe}$ rich phase might presumably account for the large differences of experimental magnetization. Finally, we suggest as a tentative overall explanation that the nominal atomic composition of the particles seems to be dependent on the particle size. $\mathrm{Cu}$ rich local regions of liquid could break farther during cooling giving rise to small particles with richer $\mathrm{Cu}$ content. This suggestion would explain the presence of $\mathrm{Cu}$ rich large aggregates in sample $\mathrm{A}$ and its subsequent important effect on the magnetic behavior.

\section{ACKNOWLEDGMENTS}

This work has been supported by the MEC of Spain: Consolider-Ingenio 2010 Contract Nos. CSD2007-0010, MAT2009-14741-C02-01, and S2009 MAT 1726; Project Nos. TSI-020100-2011-280 and IPT-2011-0893-42000.

${ }^{1}$ J. S. Garitaonandia, D. S. Schmool, and J. M. Barandiarán, Phys. Rev. B 58, 12147 (1998).

${ }^{2}$ V. Franco, J. S. Blázquez, C. F. Conde, and A. Conde, Appl. Phys. Lett. 88, 042505 (2006).

${ }^{3}$ P. Marín and A. Hernando, Appl. Phys. Lett. 89, 033508 (2006).

${ }^{4}$ A. Hernando and T. Kulik, Phys. Rev. B 49, 7064 (1994).

${ }^{5}$ G. Herzer, IEEE Trans. Magn. 25, 3327 (1989); 30(6), 4800 (1994).

${ }^{6}$ R. Schafer, A. Hubert, and G. Herzer, J. Appl. Phys. 69(8), 5325 (1991).

${ }^{7}$ A. Hernando, P. Marín, M. Vázquez, J. M. Barandiarán, and G. Herzer, Phys. Rev. B 58, 366-370 (1998).

${ }^{8}$ J. Arcas, A. Hernando, J. M. Barandiarán, C. Prados, M. Vázquez, P. Marín, and A. Neuweiler, Phys. Rev. B 58(9), 5193 (2000).

${ }^{9}$ J. Garitaonandia, P. Gorría, L. Fernández-Barquín, and J. M. Barandiarán, Phys. Rev. B 61(9), 6150 (2000).

${ }^{10}$ A. Hernando, M. Vázquez, T. Kulik, and C. Prados, Phys. Rev. B 51, 3581 (1995).

${ }^{11}$ M. Vázquez, P. Marín, H. A. Davies, and A. O. Olofinjana, Appl. Phys. Lett. 64(23), 3184 (1994).

${ }^{12}$ A. Slawska-Waniewska, P. Didukh, H. K. Lachowicz, and T. Kulik, J. Magn. Magn. Mater 215-216, 495 (2000).

${ }^{13}$ A. Slawska-Waniewska, B. Idzikowski et al., Properties and Applications of Nanocrystalline Alloys from Amorphous Precursors (Kluwer Academic, The Netherlands, 2005), pp. 123-124.

${ }^{14}$ M. Raja, K. Chattopadhyay, B. Majumdar, and A. Narayanasan, J. Alloys Compd. 297, 199 (2000).

${ }^{15}$ M. Knobel, M. L. Sánchez, P. Marín, C. Gómez-Polo, M. Vázquez, and A. Hernando, IEEE Trans. Magn. 31(6), 4009 (1995).

${ }^{16}$ J. Balogh, L. Budjoso, D. Kaptas, T. Kemeny, I. Vincze, S. Szabo, and D. L. Beke, Phys. Rev. B 61(6), 4109 (2000).

${ }^{17}$ L. Del Bianco, C. Ballesteros, J. M. Rojo, and A. Hernando, Phys. Rev. Lett. 81(20), 4500 (1998).

${ }^{18}$ J. Eckert, J. C. Holzer, C. E. Grill, and W. L. Johnson, J. Mater. Res. 7, 1751 (1992).

${ }^{19}$ E. Bonetti, L. Del Bianco, D. Fiorani, D. Rinaldi, R. Caciuffo, and A. Hernando, Phys. Rev. Lett. 83(14), 2829 (1999). 
${ }^{20}$ P. Marín, M. López, A. García-Escorial, and M. Liebich, Mater. Sci. Eng. A 449-451, 414 (2007).

${ }^{21}$ A. García-Escorial, M. Liebich, M. López, and P. Marín, J. Alloys Compd. 509, S239-S242 (2011).

${ }^{22}$ A. García Escorial, M. Lieblich, A. Hernando, A. Aragón, and P. Marín, J. Alloys. Compd. 536, S300-S303 (2012).
${ }^{23}$ A. Hernando, P. Marín, M. López, T. Kulik, L. K. Varga, and G. Hadjipanayis, Phys. Rev. B 69, 052501 (2004).

${ }^{24}$ P. Crespo, A. Hernando, R. Yavari, O. Drbohlav, and A. García-Escorial, Phys. Rev. B 48(10), 7134 (1993).

${ }^{25}$ P. Crespo, A. Hernando, and A. García-Escorial, Phys. Rev. B 49(18), 13227 (1994). 